Case Report

\title{
A Prenatally Ascertained De Novo Terminal Deletion of Chromosomal Bands 1q43q44 Associated with Multiple Congenital Abnormalities in a Female Fetus
}

\author{
Carolina Sismani, ${ }^{1}$ Georgia Christopoulou, ${ }^{2}$ Angelos Alexandrou, ${ }^{1}$ Paola Evangelidou, \\ Jacqueline Donoghue, ${ }^{2}$ Anastasia E. Konstantinidou, ${ }^{3}$ and Voula Velissariou ${ }^{2}$ \\ ${ }^{1}$ Department of Cytogenetics and Genomics, The Cyprus Institute of Neurology and Genetics, 6 International Airport Avenue, \\ Ayios Dometios, 2370 Nicosia, Cyprus \\ ${ }^{2}$ Department of Genetics and Molecular Biology, General, Maternity, and Pediatric Clinic Mitera, Erythrou Stavrou 6, \\ 15123 Athens, Greece \\ ${ }^{3}$ Department of Pathology, Medical School, University of Athens, Mikras Assias 75, 11527 Athens, Greece
}

Correspondence should be addressed to Voula Velissariou; voulavel@leto.gr

Received 21 October 2014; Revised 22 December 2014; Accepted 13 January 2015

Academic Editor: Maria Descartes

Copyright (C) 2015 Carolina Sismani et al. This is an open access article distributed under the Creative Commons Attribution License, which permits unrestricted use, distribution, and reproduction in any medium, provided the original work is properly cited.

\begin{abstract}
Terminal deletions in the long arm of chromosome 1 result in a postnatally recognizable disorder described as 1q43q44 deletion syndrome. The size of the deletions and the resulting phenotype varies among patients. However, some features are common among patients as the chromosomal regions included in the deletions. In the present case, ultrasonography at 22 weeks of gestation revealed choroid plexus cysts (CPCs) and a single umbilical artery (SUA) and therefore amniocentesis was performed. Chromosomal analysis revealed a possible terminal deletion in 1q and high resolution array CGH confirmed the terminal 1q43q44 deletion and estimated the size to be approximately $8 \mathrm{Mb}$. Following termination of pregnancy, performance of fetopsy allowed further clinical characterization. We report here a prenatal case with the smallest pure terminal 1q43q44 deletion, that has been molecularly and phenotypically characterized. In addition, to our knowledge this is the first prenatal case reported with 1q13q44 terminal deletion and Pierre-Robin sequence (PRS). Our findings combined with review data from the literature show the complexity of the genetic basis of the associated syndrome.
\end{abstract}

\section{Introduction}

Pure deletions of distal chromosome 1q result in a recognizable disorder described as 1q43q44 deletion syndrome (OMIM-612337, http://www.omim.org). Although clinical manifestations vary, most patients share characteristic features such as moderate-to-severe intellectual disability, limited to no speech, dysmorphic facial features including round face, prominent forehead, flat nasal bridge, hypertelorism, epicanthal folds, and low set ears. Hypotonia, poor growth, microcephaly, corpus callosum abnormalities (CCA), and seizures are also commonly present in these patients. The case we present in the current study is, to our knowledge, the first prenatal case with the smallest pure 1q43q44 deletion in a female fetus molecularly and phenotypically characterized and the first reported case with an association with PRS. The detailed autopsy and genetic analysis results allow further characterization, clinical correlation, and/or genotypephenotype correlation, as well as comparison with previously described prenatal and postnatal cases.

\section{Case Report}

A 32-year-old pregnant woman was referred to our lab at 22 weeks of gestation for chromosomal investigation by karyotype analysis after amniocentesis, requested due to abnormal ultrasound findings. The prospective parents are both of Greek origin and apparently healthy. This was their 

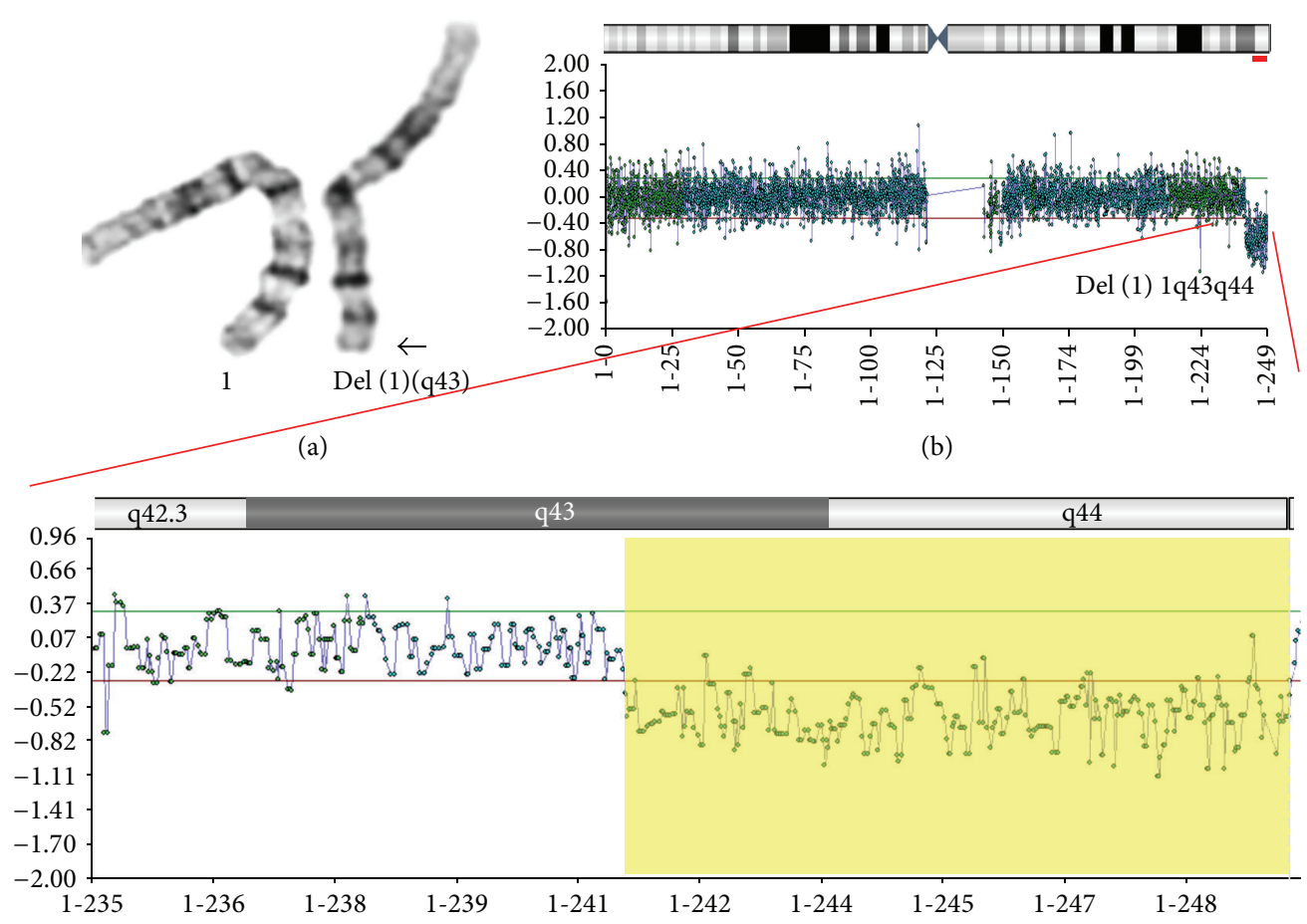

(c)

FIGURE 1: (a) Prenatal fetal karyotype. The prenatal fetal karyotype revealed a lq43 deletion most probably terminal. Arrow points to the deleted region of the long arm of chromosome 1. (b) Array-CGH results indicating the terminal deletion chromosome 1. (c) Array-CGH analysis illustrating in depth the de novo terminal deletion (highlighted) of approximately $8 \mathrm{Mb}$ in size on the long arm of chromosome 1 at chromosomal band 1q43 extending to band 1q44 (location: 241,178,091-249,224,121 using build GRCh37 (hg19)).

first pregnancy (gravida 1, para 0) and no previous medical or obstetrical history was recorded. The pregnancy had been conceived spontaneously and was unremarkable until this point. Routine ultrasound examination at 22 weeks of gestation revealed choroid plexus cysts (CPCs) and a single umbilical artery (SUA). Chromosomal analysis was performed on amniotic fluid cells. Conventional GTG-banding at 550 band level was applied and revealed a female fetus with a borderline visible deletion on distal 1q, most likely terminal (46,XX,del(1)(q43), Figure 1(a)). Parental karyotypes revealed that the deletion was de novo. MLPA was subsequently performed using the P036 and P069 subtelomeric probe mixes (MRC-Holland) on DNA isolated from cultured amniotic fluid cells and confirmed the telomeric nature of the 1q deletion (data not shown). To further delineate the breakpoint of the deletion array-CGH (Comparative Genomic Hybridization) was carried out using the Cytochip Oligo array (BlueGnome-version 1.1) with 105,000 oligos according to the recommendations of the manufacturer. Array-CGH analysis confirmed the results, revealing a female profile with a deletion of approximately $8 \mathrm{Mb}$ in size on the long arm of chromosome 1 from chromosomal band 1q43 extending to 1q44 (location: 241,178,091-249,224,121 using build GRCh37 (hg19), Figures 1(b) and 1(c)). No other copy number changes were detected by array-CGH indicating a pure deletion of the region. The deleted region contains 23 OMIM genes listed in Table 1.
Genetic counseling was offered to the couple and termination of the pregnancy was decided at 28 weeks of gestation. The female fetus was sent for autopsy (a written consent was also obtained from the couple for the publication including fetopsy photos).

At autopsy the fetus was found to be symmetrically growth restricted, weighing $838 \mathrm{~g}$ (below the 10th centile for 28 weeks-gestation) and measuring $33.5 \mathrm{~cm}$ in crownheel length, $22.5 \mathrm{~cm}$ in crown-rump length, and $46.5 \mathrm{~cm}$ in foot length, the body measurements being more appropriate for 25 -week gestation. The head circumference $(22.8 \mathrm{~cm})$ fell below the 1st centile for 28-week gestation. External craniofacial features included microcephaly and microretrognathia with $U$-shaped clefting of the hard and soft palate (Pierre-Robin sequence) (Figure 2). The tip of the tongue was noted to be mildly bifid. The clitoris appeared large, with normally formed and sized labia while the anogenital distance appeared shortened. Internally, dissection of the heart revealed an atrial septal defect (ASD) secundum type. The brain weight was low ( $84 \mathrm{~g}$; ref. for 28/40 weeks $147 \mathrm{~g}$ ) corresponding to 23 -week gestation, and the brain-to-liverweight ratio was reduced (1.69; ref. 2.5-4), altogether indicating micrencephaly. The cerebellar vermis appeared small. Choroid plexus cysts seen at prenatal ultrasound at 22-week gestation were not confirmed, likely to have resolved in the meantime. Microscopy showed neuroglial migration defects in the periventricular and subcortical cerebral white matter. 
TABLE 1: Genes included in the deleted region and associated phenotypes.

\begin{tabular}{|c|c|c|}
\hline Gene/locus name & $\begin{array}{l}\text { Gene/locus } \\
\text { MIM number }\end{array}$ & Phenotype/gene function \\
\hline RGS7 & 602517 & $\begin{array}{l}\text { Inhibits signal transduction by increasing the GTPase activity of } \\
\text { G protein alpha subunits }\end{array}$ \\
\hline FH, HLRCC, MCUL1 & 136850 & Leiomyomatosis and renal cell cancer. Fumarase deficiency \\
\hline KMO & 603538 & $\begin{array}{l}\text { Catalyzes the hydroxylation of L-kynurenine (L-Kyn) to form } \\
\text { 3-hydroxy-L-kynurenine for synthesis of quinolinic acid }\end{array}$ \\
\hline$O P N 3, E C P N$ & 606695 & $\begin{array}{l}\text { Opsins are members of the guanine nucleotide-binding protein } \\
\text { (G protein)-coupled receptors that are expressed in extraocular } \\
\text { tissues }\end{array}$ \\
\hline CHML, REP2 & 118825 & Binds unprenylated Rab proteins \\
\hline EXO1, HEX1 & 606063 & $5^{\prime}->3^{\prime}$ double-stranded DNA exonuclease activity \\
\hline CEP170, KIAA0470 & 613023 & Plays a role in microtubule organization \\
\hline SDCCAG8, CCCAP, SLSN7 & 613524 & Senior-Loken syndrome 7 \\
\hline$A K T 3, P K B G, M P P H$ & 611223 & $\begin{array}{l}\text { Megalencephaly-polymicrogyria-polydactyly-hydrocephalus } \\
\text { syndrome }\end{array}$ \\
\hline ZBTB18, ZNF238, RP58, MRD22 & 608433 & Mental retardation, autosomal dominant 22 \\
\hline ADSS & 103060 & $\begin{array}{l}\text { Has an important role in the de novo and salvage pathway of } \\
\text { purine nucleotide biosynthesis }\end{array}$ \\
\hline DESI2, PPPDE1 & 614638 & $\begin{array}{l}\text { Protease which may deconjugate SUMO from some substrate } \\
\text { proteins }\end{array}$ \\
\hline COX20, FAM $36 A$ & 614698 & Protect as-yet-unassembled Cox 2 from degradation \\
\hline$H N R N P U$ & 602869 & $\begin{array}{l}\text { Component of the CRD-mediated complex that promotes MYC } \\
\text { mRNA stabilization. Binds to pre-mRNA. }\end{array}$ \\
\hline KIF26B & 614026 & Essential for embryonic kidney development \\
\hline SMYD3 & 608783 & Histone methyltransferase \\
\hline$T F B 2 M$ & 607055 & $\begin{array}{l}\text { Required for basal transcription of mitochondrial DNA, } \\
\text { probably via its interaction with POLRMT and TFAM }\end{array}$ \\
\hline CNST & 613439 & Required for targeting of connexins to the plasma membrane \\
\hline AHCTF1, ELYS & 610853 & $\begin{array}{l}\text { Required for the assembly of a functional nuclear pore complex } \\
\text { on the surface of chromosomes as nuclei form at the end of } \\
\text { mitosis }\end{array}$ \\
\hline ZNF124 & 194631 & $\begin{array}{l}\text { Affiliated with the lncRNA class and may be involved in } \\
\text { transcriptional regulation }\end{array}$ \\
\hline ZNF496, NIZP1, ZFP496 & 613911 & $\begin{array}{l}\text { DNA-binding transcription factor that can both act as an } \\
\text { activator and a repressor }\end{array}$ \\
\hline NLRP3, CIAS1, FCU, FCAS, NALP3, PYPAF1 & 606416 & $\begin{array}{l}\text { CINCA syndrome, Cold-induced autoinflammatory syndrome, } \\
\text { familial Muckle-Wells syndrome }\end{array}$ \\
\hline OR13G1 & 611677 & Odorant receptor (potential) \\
\hline
\end{tabular}

The placenta weighed $169 \mathrm{~g}$ (around the 25th centile for 28/40 weeks) and the fetoplacental ratio was within normal range. Histology showed abnormal development of the placental parenchyma, with uneven villous maturation and features of fetal obstructive vasculopathy. The umbilical cord had 3 vessels, but one umbilical artery was seen to be collapsed, showing luminal occlusion and no evidence of blood flow at the fetal edge.

\section{Discussion}

The prenatal case presented in this study involves a terminal 1q43q44 deletion which in postnatal cases has been associated with a syndrome with specific clinical features (OMIM612337, http://www.omim.org). Although manifestations may vary, our fetus had features overlapping the 1q43q44 deletion phenotype, as expected. Such characteristics are microcephaly, microretrognathia, cleft palate, cardiac defect, and small cerebellar vermis. Only three cases of terminal 1q deletions have been described during prenatal diagnosis. The first was detected in a fetus at 19 weeks with omphalocele, cerebral ventriculomegaly, and increased nuchal fold with a breakpoint at 1q41 [1]. The second was detected in a fetus at 21 weeks with hydrocephalus, ventriculomegaly, and corpus callosum agenesis with a breakpoint at 1q42.3 [2]. The third, with a breakpoint at 1q43, was detected by chorionic villous sampling (CVS) in a 12 -week fetus with severe 

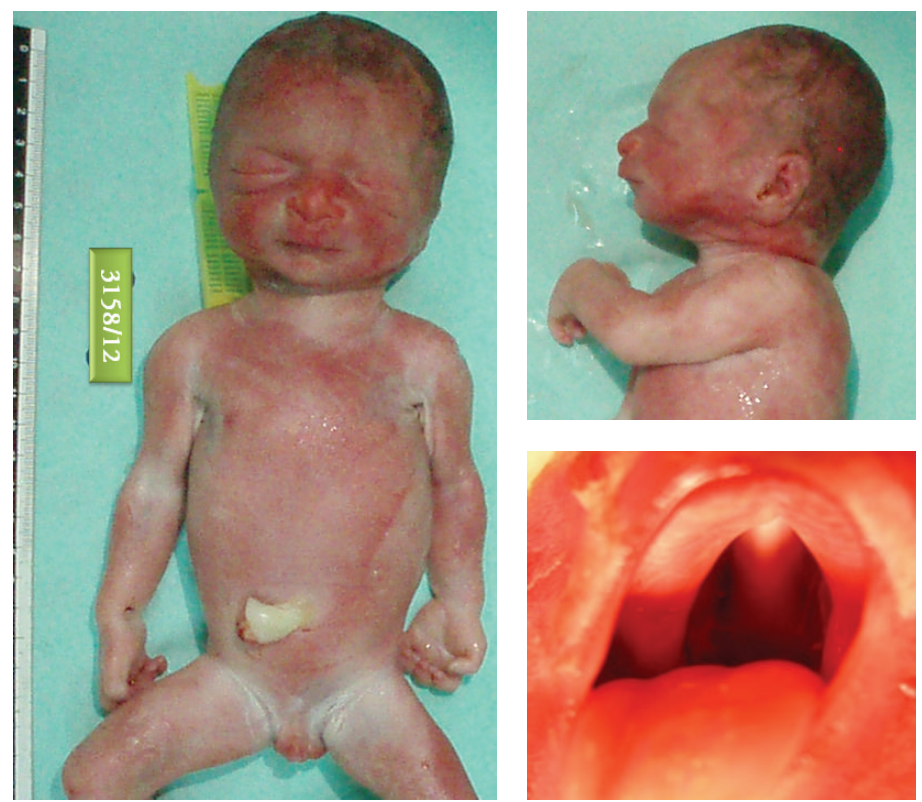

FIgURE 2: Autopsy findings revealed multiple congenital malformations. The figure shows microretrognathia and U-shaped cleft palate (Pierre-Robin sequence) as well as a large clitoris with normally formed labia.

microgenia, nasal bone aplasia, SUA, cardiac anomaly, and hyperechogenic bowel. At 16 weeks, the suspected structural abnormalities were confirmed and in addition intrauterine growth retardation (IUGR) and microcephaly were observed [3]. In the first two cases the deletions were considerably larger than in our case and easily detected during cytogenetic analysis. In the third case, although there are common clinical findings with our case such as microcephaly, SUA, and IUGR, autopsy was not performed and a detailed comparison of the phenotype between the two cases is not possible. For example, the authors report severe microgenia, which at autopsy could prove to be microretrognathia with clefting of the hard and soft palate (PRS), also present in our case. Furthermore, the breakpoint of the deletion was only determined by chromosomal analysis and it appears that the deletion is again significantly larger than ours. Finally, array CGH studies were performed only in the second case where the size of the deletion was estimated at $13.4 \mathrm{Mb}$, which is significantly larger than that in our case $(8 \mathrm{Mb})$. The antenatal features of the previously three reported del(1q) syndrome prenatal cases and of our present case are summarized in Table 2 .

Two recent studies $[5,6]$ in patients with 1q43q44 microdeletion clarified the phenotype/genotype correlation and proposed three distinct critical regions. The first encompassing ZNF238 was associated with corpus callosum anomalies (CCA) and the second includes AKT3 with microcephaly (MIC), while the third contains the two coding genes FAM36A, HNRNPU and the noncoding gene NCRNA00201 with seizures. The implication of ZNF238 in CCA has also been supported by the study of a patient with 1q44 microdeletion and dysmorphic features, seizures, hypotonia, marked developmental delay, and dysgenesis of the corpus callosum [7]. In the case presented here, AKT3, ZNF238, FAM36A, and $H N R N P U$ are all included in the deletion. Fetoscopy showed evidence of microcephaly which is in agreement with the implication of AKT3 in MIC as has already been proposed by others $[5,6,8]$. However, although ZNF238 is absent, CCA was not observed, demonstrating the complexity of CCA genetics. Incomplete penetrance associated with deletion of ZNF238 could be an explanation. This has also been proposed in a study in which two patients with moderate-to-severe intellectual disability, craniofacial anomalies, and seizures carrying 1q44 microdeletion including both ZNF238 and AKT3 both had MIC, but only the one presented with CCA [8].

The size of the deletion in our case is comparable to that of a boy with intellectual disability and multiple anomalies where the lqter deletion was not microscopically visible [4]. At 20-week gestational age a cystic structure in the gastric region was seen on ultrasound which subsequently disappeared, while from 30 weeks IUGR was present. After birth major anomalies were detected and at the age of 5 years severe intellectual disability was also observed. Common features with our case are IUGR, microretrognathia, microcephaly, hypoplastic vermis, and genital abnormalities. However, the mapping of the deletion was performed by microsatellite marker analysis and not array CGH and consequently the exact comparison cannot be made, although the two cases appear to be very similar (Table 2).

The postmortem examination in our case also revealed the presence of PRS, that is, the combination of microretrognathia and posterior soft palate cleft. To date this has been strongly associated with SOX9 either directly or by position effect $[9,10]$. It has also been associated with specific gene mutations and various chromosomal abnormalities including deletions, translocations, and duplications [11]. Recently, it has been associated with microdeletion 4q21, microdeletion 5q23, and microduplication 16p13.3 [12-14]. 
TABLE 2: Clinical features and genetic findings in one postnatal with a very similar deletion size and three prenatal reported cases with deletions spanning chromosomal region 1q41 to 1q44 and comparison with our case.

\begin{tabular}{|c|c|c|c|c|c|}
\hline & $\begin{array}{c}\text { Rotmensch et al. [1] } \\
\text { prenatal }\end{array}$ & $\begin{array}{c}\text { Chen et al. [2] } \\
\text { prenatal }\end{array}$ & $\begin{array}{c}\text { Wagner et al. [3] } \\
\text { prenatal }\end{array}$ & $\begin{array}{l}\text { van Bever et al. }[4] \\
\text { postnatal }\end{array}$ & $\begin{array}{l}\text { Our case } \\
\text { prenatal }\end{array}$ \\
\hline Karyotype & $\begin{array}{c}\text { 46,XY, } \\
\operatorname{del}(1)(\mathrm{q} 41)\end{array}$ & $\begin{array}{c}\text { 46,XX, } \\
\operatorname{del}(1)(\mathrm{q} 42.3)\end{array}$ & $\begin{array}{c}\text { 46, XX, } \\
\operatorname{del}(1)(\mathrm{q} 43)\end{array}$ & $46, X Y$ & $\begin{array}{c}\text { 46, XX, } \\
\operatorname{del}(1)(\mathrm{q} 43 \mathrm{q} 44)\end{array}$ \\
\hline Light microscope & Detected & Detected & Detected & Not detected & Detected \\
\hline Array CGH & Not performed & $13.4 \mathrm{Mb}$ & Not performed & $7.7-8.1 \mathrm{Mb}^{\S}$ & $8 \mathrm{Mb}$ \\
\hline Parental karyotypes & Normal & Normal & Normal & Normal & Normal \\
\hline Gestational age & 2nd trimester & $\begin{array}{l}\text { 2nd and 3rd } \\
\text { trimester }\end{array}$ & $\begin{array}{l}\text { 1st and 2nd } \\
\text { trimester }\end{array}$ & $\begin{array}{l}\text { 2nd and 3rd } \\
\text { trimester }\end{array}$ & $\begin{array}{l}\text { 2nd and } 3 r d \\
\text { trimester }\end{array}$ \\
\hline IUGR & - & + & + & + & + \\
\hline $\begin{array}{l}\text { Increased nuchal } \\
\text { translucency/fold }\end{array}$ & + & - & - & - & - \\
\hline Nasal bone absence/hypoplasia & - & - & + & + & - \\
\hline Hyperechogenic bowel & - & - & + & - & - \\
\hline Single umbilical artery & - & - & + & - & + \\
\hline Omphalocele & + & - & - & - & - \\
\hline Microcephaly/micrencephaly & * & - & + & * & * \\
\hline Micrognathia/microgenia & - & - & + & * & * \\
\hline Microretrognathia & - & - & - & * & * \\
\hline Cleft palate & - & - & - & - & * \\
\hline Hydrocephalus & - & + & - & - & - \\
\hline Cerebral anomalies & + & - & - & * & $*$ \\
\hline $\begin{array}{l}\text { Corpus callosum } \\
\text { agenesis/hypoplasia }\end{array}$ & - & + & - & $*$ & - \\
\hline Hypoplastic vermis & - & - & - & $*$ & $*$ \\
\hline Choroid plexus cysts & - & - & - & - & + \\
\hline Urogenital anomalies & - & - & - & * & * \\
\hline Cardiac anomaly & - & + & + & $*$ & $*$ \\
\hline Fetopsy & - & - & - & $* *$ & + \\
\hline
\end{tabular}

${ }^{\S}$ Performed by microsatellite marker analysis; IUGR: intrauterine growth retardation.

-: not specifically mentioned or undetected; $*$ : initially detected at birth or after termination of pregnancy by observation only or fetopsy; $* *:$ born; +: present.

To our knowledge, this is the first reported case with pure lq43q44 deletion and PRS. There is a single report on a family with cerebellar hypoplasia and PRS, partially resembling our case clinically; however array CGH and subtelomeric FISH revealed no chromosomal imbalances [9]. Our case further supports the fact that PRS conceals considerable etiological heterogeneity and that various chromosomal regions harbor genes responsible for the PRS phenotype, including 1q43q44.

In addition to PRS, the present case is the first in which neuroglial migration defects were detected in the brain, whereas in previous deletion 1q43q44 cases brain abnormalities included delayed myelination, cerebral atrophy, and hydrocephalus $[2,8]$.

Our findings are in agreement with most reports, the main disagreement with previous reports relates to gene ZNF238 which although is included in the deleted region no corpus callosum abnormalities were identified. The possibility of identifying specific ultrasonographic markers for 1q43q44 deletion during pregnancy is not clear at the moment because of the limited number of cases described prenatally.
All the above findings highlight the complexity of gene implication/interaction, reflected in the difficulty of genotype-phenotype correlations, and the fact that probable additional mechanisms such as incomplete penetrance, variable expressivity, or multigenic factors may also influence phenotypic expression. Reporting such cases may contribute to better understanding of these issues.

\section{Conflict of Interests}

The authors declare that there is no conflict of interests regarding the publication of this paper.

\section{Authors' Contribution}

Carolina Sismani and Georgia Christopoulou equally contributed to this paper. 


\section{References}

[1] S. Rotmensch, M. Liberati, J. S. Luo, G. Tallini, M. J. Mahoney, and J. C. Hobbins, "Prenatal diagnosis of a fetus with terminal deletion of chromosome 1 (q41)," Prenatal Diagnosis, vol. 11, no. 11, pp. 867-873, 1991.

[2] C. P. Chen, S. R. Chern, F. J. Tsai et al., "Prenatal diagnosis of partial monosomy 1q (1q42.3 $\rightarrow$ qter) associated with hydrocephalus and corpus callosum agenesis," Genetic Counseling, vol. 21, no. 4, pp. 451-455, 2010.

[3] N. Wagner, E. Guengoer, U. A. Mau-Holzmann et al., "Prenatal diagnosis of a fetus with terminal deletion of chromosome 1 (q43) in first-trimester screening: is there a characteristic antenatal 1q deletion phenotype? A case report and review of the literature," Fetal Diagnosis and Therapy, vol. 29, no. 3, pp. 253-256, 2011.

[4] Y. van Bever, L. Rooms, A. Laridon et al., "Clinical report of a pure subtelomeric 1qter deletion in a boy with mental retardation and multiple anomalies adds further evidence for a specific phenotype," American Journal of Medical Genetics Part A, vol. 135A, no. 1, pp. 91-95, 2005.

[5] B. C. Ballif, J. A. Rosenfeld, R. Traylor et al., "High-resolution array CGH defines critical regions and candidate genes for microcephaly, abnormalities of the corpus callosum, and seizure phenotypes in patients with microdeletions of 1q43q44," Human Genetics, vol. 131, no. 1, pp. 145-156, 2012.

[6] S. C. S. Nagamani, A. Erez, C. Bay et al., "Delineation of a deletion region critical for corpus callosal abnormalities in chromosome 1q43-q44," European Journal of Human Genetics, vol. 20, no. 2, pp. 176-179, 2012.

[7] S. J. Perlman, S. Kulkarni, L. Manwaring, and M. Shinawi, "Haploinsufficiency of ZNF238 is associated with corpus callosum abnormalities in 1q44 deletions," The American Journal of Medical Genetics, Part A, vol. 161, no. 4, pp. 711-716, 2013.

[8] G. Thierry, C. Bénéteau, O. Pichon et al., "Molecular characterization of 1q44 microdeletion in 11 patients reveals three candidate genes for intellectual disability and seizures," American Journal of Medical Genetics, Part A, vol. 158, no. 7, pp. 1633-1640, 2012.

[9] J. K. Rainger, S. Bhatia, H. Bengani et al., "Disruption of SATB2 or its long-range cis-regulation by SOX 9 causes a syndromic form of Pierre Robin sequence," Human Molecular Genetics, vol. 23, no. 10, Article ID ddt647, pp. 2569-2579, 2014.

[10] S. Benko, J. A. Fantes, J. Amiel et al., "Highly conserved noncoding elements on either side of SOX9 associated with Pierre Robin sequence," Nature Genetics, vol. 41, no. 3, pp. 359-364, 2009.

[11] K. Izumi, L. L. Konczal, A. L. Mitchell, and M. C. Jones, "Underlying genetic diagnosis of pierre robin sequence: retrospective chart review at two children's Hospitals and a systematic literature review," Journal of Pediatrics, vol. 160, no. 4, pp. 645.e2-650.e2, 2012.

[12] E. Bhoj, S. Halbach, D. Mcdonald-Mcginn et al., "Expanding the spectrum of microdeletion 4q21 syndrome: a partial phenotype with incomplete deletion of the minimal critical region and a new association with cleft palate and pierre robin sequence," The American Journal of Medical Genetics-Part A, vol.161, no. 9, pp. 2327-2333, 2013.

[13] M. Ansari, J. K. Rainger, J. E. Murray et al., "A syndromic form of Pierre Robin sequence is caused by $5 \mathrm{q} 23$ deletions encompassing FBN2 and PHAX," European Journal of Human Genetics, vol. 57, no. 10, pp. 587-595, 2014.
[14] M. Sun, H. Zhang, G. Li et al., "16p13.3 duplication associated with non-syndromic pierre robin sequence with incomplete penetrance," Molecular Cytogenetics, vol. 7, no. 1, article 76, 2014. 


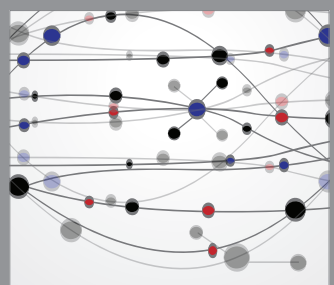

The Scientific World Journal
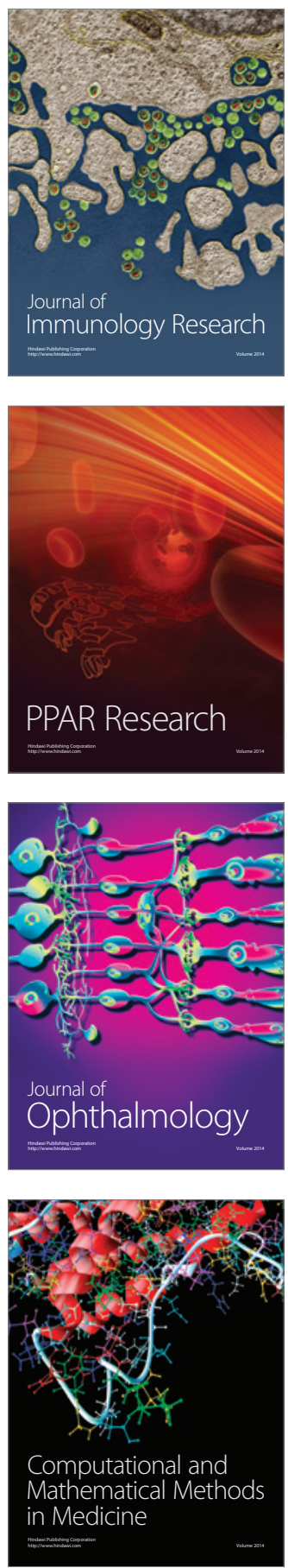

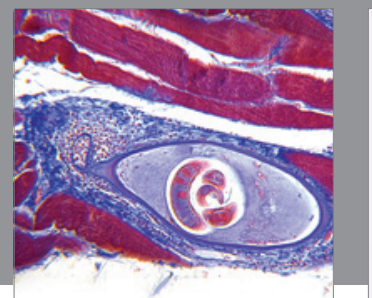

Gastroenterology

Research and Practice
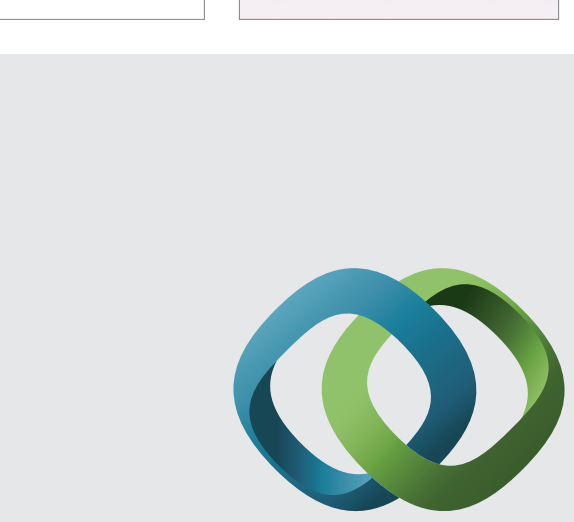

\section{Hindawi}

Submit your manuscripts at

http://www.hindawi.com
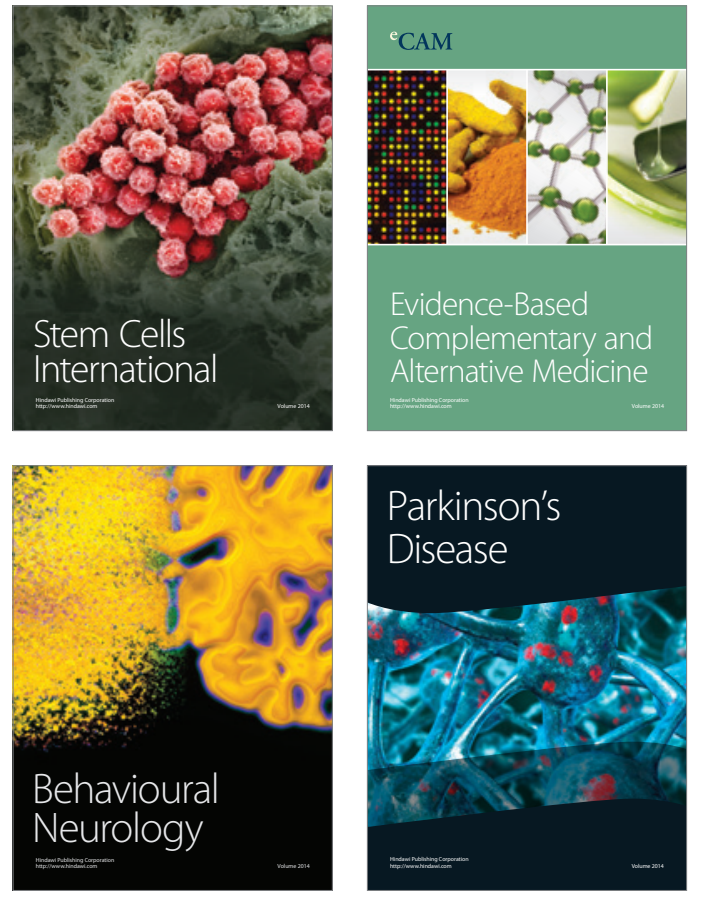
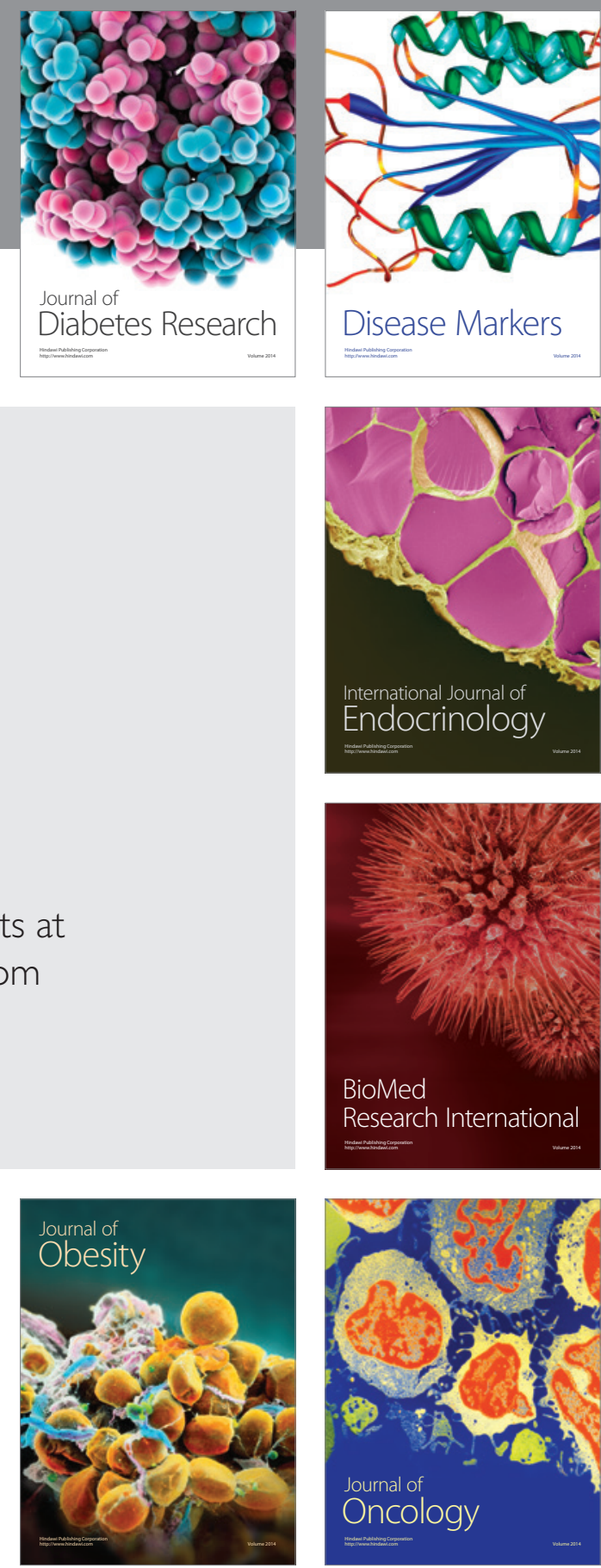

Disease Markers
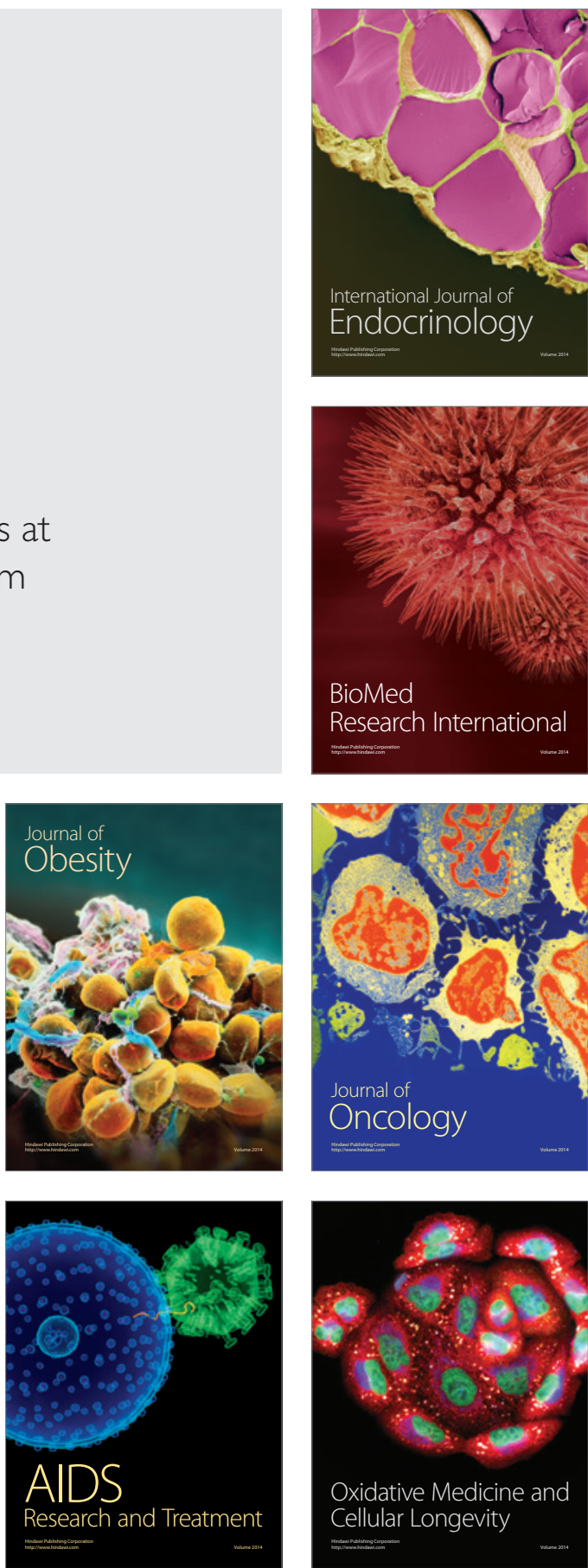